\title{
A Química no Estatuto da Faculdade de Filosofia de Coimbra (1772): origens de uma Disciplina
}

\author{
Chemistry in the Statute of the Faculty of Philosophy of Coimbra (1772): \\ origins of a School Subject
}

La Química en el Estatuto de la Facultad de Filosofía de Coimbra (1772):

origenes de una Asignatura

\author{
Ademir Valdir dos Santos \\ Universidade Federal de Santa Catarina (Brasil) \\ http://lattes.cnpq.br/3561356499117598 \\ http://orcid.org/0000-0002-5958-689X \\ ademirvaldirdossantos@gmail.com \\ Renato da Silva Custódio \\ Universidade Federal de Santa Catarina (Brasil) \\ http://lattes.cnpq.br/3558924452371552 \\ https://orcid.org/0000-0003-0424-3790 \\ renatodsc2@gmail.com
}

\section{Resumo}

Objetiva caracterizar a origem e desenvolvimento da disciplina de Química no ambiente de embates entre a tradição humanista e a racionalidade científica em Portugal, no século XVIII. A metodologia empregada é a Análise de Conteúdo do Estatuto da Faculdade de Filosofia de Coimbra, considerando um diálogo com Chervel (1990) sobre a história das disciplinas escolares. Os resultados apontam aspectos referentes à Química em quatorze diretrizes. A Análise de Conteúdo permitiu construir três categorias relacionadas à gênese, organização e desenvolvimento da disciplina: objetivos, conteúdos e metodologia, com base numa categorização que admite o movimento entre a Química enquanto ciência de referência e como disciplina escolar, destacando palavras-chave como examinar, separar, corpo, substância, composição, afinidade, propriedade, combinação, misturas, comparação, lente/professor, teoria e experiência/prática/laboratório. Foram analisadas finalidades reais relacionadas às práticas escolares - e finalidades de objetivo - prescritas no texto oficial, delineando a Química enquanto disciplina vinculada às transformações históricas.

Palavras-chave: História das disciplinas escolares. Química. Estatuto da Faculdade de Filosofia de Coimbra. 


\begin{abstract}
It aims to characterize the origin and development of the discipline of Chemistry in the environment of clashes between the humanist tradition and scientific rationality in Portugal in the 18th century. The methodology used is the Content Analysis of the Statute of the Faculty of Philosophy of Coimbra, considering a dialogue with Chervel (1990) on the history of the school subjects. The results point to aspects related to Chemistry in fourteen guidelines. Content Analysis allowed to construct three categories related to the genesis, organization and development of the discipline: objectives, contents and methodology, based on a categorization that admits the movement between Chemistry as a reference science and as a school discipline, highlighting key words like examine, separating, body, substance, composition, affinity, property, combination, mixtures, comparison, lens / teacher, theory and experiment / practice / laboratory. Real aims related to school practices - and objective aims - prescribed in the official text, were analyzed, outlining Chemistry as a discipline linked to historical transformations.
\end{abstract}

Keywords: History of school subjects. Chemistry. Statute of the Faculty of Philosophy of Coimbra

\title{
Resumen
}

Tiene como objetivo caracterizar el origen y desarrollo de la disciplina química en el ambiente de enfrentamientos entre la tradición humanista y la racionalidad científica en Portugal en el siglo XVIII. La metodología empleada es el Análisis de Contenido del Estatuto de la Facultad de Filosofía de Coimbra, considerando un diálogo con Chervel (1990) sobre la historia de las disciplinas escolares. Los resultados apuntan aspectos referentes a la Química en catorce directrices. El Análisis de Contenido permitió construir tres categorías relacionadas con la génesis, organización y desarrollo de la disciplina: objetivos, contenidos y metodología, con base en una categorización que admite el movimiento entre la Química como ciencia de referencia y como asignatura escolar, destacando palabras clave como examinar, separación, cuerpo, sustancia, composición, afinidad, propiedad, combinación, mezclas, comparación, lente / profesor, teoría y experiencia / práctica / laboratorio. Se analizaron finalidades reales - relacionadas a las prácticas escolares - y finalidades de objetivo - prescritas en el texto oficial, delineando la Química como disciplina vinculada a las transformaciones históricas.

Palabras clave: Historia de las disciplinas. Química. Estatuto de la Facultad de Filosofía de Coimbra. 


\section{Introdução}

Este artigo é resultante de uma pesquisa que tem como propósito traçar um caminhar histórico da disciplina de Química, considerando sua gênese e posterior institucionalização no campo educacional. Destacamos uma fonte particular, levando em conta o seu protagonismo e caráter seminal: o novo Estatuto da Faculdade de Filosofia, exarado em 1772, oriundo da Reforma da Universidade de Coimbra. Partimos da hipótese de que, no contexto dos embates entre a tradição humanista e a emergente racionalidade científica de inspiração iluminista que motivou o processo reformador empreendido pelo governo luso à época, o Estatuto expressa, sob perspectiva histórica, características das origens, do desenvolvimento e da organização da disciplina de Química.

O texto está estruturado em quatro seções. Inicialmente, apresentamos a metodologia empregada, detalhando o tratamento de análise e teórico relacionado. Em seguida, trazemos uma breve abordagem contextual sobre a Reforma na Universidade de Coimbra. Na parte mais densa, que contém os elementos de ordem analítica e interpretativa, nos debruçamos sobre o Estatuto da Faculdade de Filosofia de Coimbra. Por fim, apresentamos algumas considerações vinculadas aos resultados.

\section{A Metodologia Empregada: apontamentos}

A metodologia tem como inspiração a exploração de um corpo teórico vinculado à História da Educação, elaborado por André Chervel (1990), que apresenta uma discussão conceitual sobre a história das disciplinas escolares, argumentando sobre sua definição e constituição, considerando suas funções no plano cultural, questionando suas finalidades e, ao lado disto, explorando as formas de sua escrita. No diálogo com tal referência, realizamos sua combinação com o método de Análise de Conteúdo, definido por Laurence Bardin (2004), aplicado à atividade analítica da fonte documental eleita.

Quanto àquela primeira opção metodológica, ressaltamos o embasamento proposto por Chervel, particularmente quando explicita características inovadoras quanto aos estudos que envolvem a produção de conhecimento sobre as disciplinas escolares. Pois segundo ele, há uma postura epistêmica que engloba a constituição histórica e social de determinada disciplina, parte de leis e definições inseridas no plano cultural e chega até sua inserção no ambiente escolar. O autor também apresenta aspectos sobre os conceitos e a terminologia que envolvem o vocábulo disciplina e as etimologias conexas. Por conseguinte, é necessário apresentar um diálogo entre a constituição e as finalidades de uma disciplina. Apresentando atributos sócio-políticos ou religiosos, por exemplo, tais finalidades se encaixam em determinada época, tendo como principal destinação o tipo de ensino aos quais são dirigidas (CHERVEL, 1990, p. 190).

Destacamos agora a Análise de Conteúdo, segundo a qual a pesquisa lança luzes sobre um corpus documental específico. Inicialmente, o procedimental solicita a denominada leitura flutuante, que embora possa ser repetida várias vezes, significa um primeiro contato com o documento eleito, prestando-se à coleta de dados. Sua rigorosa aplicação auxilia na detecção de particularidades inseridas na escrita. Esta sistemática tem como consequência a geração de um apanhado textual que apresenta novas características em relação ao seu texto original. Com esta exploração e uma concomitante classificação de termos, resultam as palavras-chave, das quais é possível extrair atributos que possibilitarão um foco à pesquisa (BARDIN, 2004, p. 40). 
Considerando-se que o corpus documental é o Estatuto da Faculdade de Filosofia de Coimbra, as palavras-chave retiradas da fonte poderão, uma vez que estão impregnadas de historicidade, ratificar alguns elementos característicos da disciplina de Química. Segundo Bardin (2004), além da detecção das palavras-chave, indicar a sua frequência ao longo do texto facilita a análise. Com base nisso, é possível a adoção de categorias iniciais que, $a$ priori, dialogam com os objetivos da investigação. Esta etapa corresponde à codificação, compreendendo a enumeração de termos, sua análise quantitativa e qualitativa, permitindo atingir uma representação de conteúdos presentes no documento, os quais servirão como índices de análise, que no momento seguinte serão categorizados e explorados. Chega-se então à fase da inferência e da interpretação, momento em que o pesquisador busca captar tanto os conteúdos explícitos como aqueles escondidos, resultando na possibilidade de comparação entre as categoriais iniciais, na busca por evidenciar elementos de similaridade ou de diferenciação. Gera-se, por fim, o agrupamento terminológico que resulta nas categorias finais (BARDIN, 2004, p. 97-137).

\section{A Reforma da Universidade de Coimbra}

Durante o século XVIII, Portugal sofreu transformações sociais, econômicas e políticas, fato que repercutiu no âmbito educacional. O controle jesuítico sobre as instituições educativas, até aquele momento hegemônico, começou a sofrer questionamentos em relação ao método tradicional de ensino, intensificados com a difusão de ideais iluministas modernizadores. Com isso, o desenvolvimento do Império se inicia pela irradiação de aspirações empiristas e utilitaristas, dentro dos mais diversos setores sociais e econômicos da sociedade portuguesa (SAVIANI, 2011, p. 80). Na busca pela inserção de aspectos do esclarecimento racional que se espalhava pela Europa, os portugueses depositaram na educação uma concentração de esforços como chave para uma mudança e buscaram libertá-la do monopólio jesuítico. Nesta conjuntura, o ataque aos jesuítas vai tomando corpo, sendo que a Reforma da Universidade de Coimbra, organizada pelo Marquês de Pombal, torna-se um marco da influência iluminista em Portugal (GAUER, 1996, p. 30-1).

Foi com a chegada de Dom José I ao poder que Portugal iniciou a adesão ao pensamento esclarecido em voga, tendo como um dos focos o campo educacional. A nomeação de Sebastião de Carvalho e Melo como ministro da Secretaria do Exterior e da Guerra, no ano de 1750, é um marco para a introdução das aspirações da Filosofia das Luzes. Em 1759, o agora intitulado Marquês de Pombal, através do Alvará de 28 de junho, instituiu o fechamento dos colégios jesuítas em toda corte portuguesa e em suas colônias, instaurando as aulas régias (CARDOSO, 2004). Cabe destacar a Reforma dos Estudos Maiores, tendo como alvo a Universidade de Coimbra, esforço vigoroso para o predomínio de uma educação científica. É com base nesta Reforma que foram produzidos dois documentos: inicialmente, o Compêndio Histórico da Universidade de Coimbra, de 1771; depois os novos Estatutos da Universidade de Coimbra, publicados no ano seguinte.

Entendemos necessário salientar algumas características sobre a elaboração e constituição do Estatuto da Faculdade de Filosofia de Coimbra, fruto do caráter reformista. Segundo Saviani (2011, p. 90-1), antes da Reforma a Universidade de Coimbra contava com quatro faculdades: Teologia, Cânones, Direito e Medicina, as quais apresentaram relevantes mudanças após a Reforma. Por exemplo, houve a inserção de novas disciplinas e mudanças nas cargas horárias exigidas para a formação. Além destas modificações, houve a criação de duas novas Faculdades: a de Matemática e a de Filosofia (GAUER, 1996, p. 107). 
Estas novas instituições foram constituídas com características modernas, já que, dentro da Faculdade de Filosofia, haviam estudos relacionados às ciências naturais. O curso de Filosofia tinha duração de quatro anos, nos quais eram ensinadas filosofia racional e moral, história natural, física experimental e química prática e teórica. Apresentava um aspecto pedagógico e educacional condizente com o esclarecimento de matiz iluminista, pois propalava o rompimento com a filosofia escolástica de Aristóteles e incorporava o chamado método sintético demonstrativo, no qual o professor devia proporcionar uma imagem geral da disciplina através da redução da matéria a um conjunto doutrinal ordenado e sistemático, subordinando a evolução expositiva a uma linha de crescente complexidade (NUNES, 2011, p. 12). Os alunos formavam dois grupos: de um lado, os ordinários, que se dedicavam aos estudos de forma optativa ou como preparação para a profissão que seguiriam; de outro, os denominados como obrigados, compelidos ao estudo da filosofia ou da matemática como prérequisito das Faculdades a que se dirigiam (SAVIANI, 2011, p. 92).

Pautado por caráter científico, os Estatutos orientavam um caminho que concebia a natureza como um espaço em que o homem poderia agir visando o progresso. Esta visão moderna de ciência, baseada na observação, tão característica do século XVIII, desmembrou a filosofia da ciência. Logo, a Reforma imprime ao processo educativo a marca de atender ao conhecimento das coisas da natureza, o que iria determinar o espírito e o modo de relação dos sujeitos aprendizes com determinadas disciplinas.

[...] encaminhou uma linha de pensamento e ação que fosse consentânea com a realidade vivenciada. A ligação entre teoria e prática é evidenciada em toda a proposta de Reforma, Compêndio Histórico e Estatutos. A idade moderna inverteu o pólo de atenção, centralizando no sujeito a questão do conhecimento. $\mathrm{O}$ aluno, para os reformadores deveria a partir da observação e da experiência formular as bases do conhecimento da natureza. (GAUER, 1996, p. 115).

\section{Ab Ovo: o Estatuto da Faculdade de Filosofia de Coimbra como Nascedouro da Disciplina de Química}

Uma das pistas sobre a origem e desenvolvimento dos estudos e conteúdos da disciplina de Química, assim como quanto ao seu ensino em Portugal, tem como base um documento proveniente da Reforma da Universidade de Coimbra.

[...] um dos textos mais objetivos sobre o ensino de Química que se tem acesso, ainda na sua forma original, é aquele que está nos estatutos da Universidade de Coimbra, editado em 1772, por ocasião de sua Reforma. Este estatuto foi publicado fac-similarmente quando das comemorações do seu bicentenário [...] Mais que ser um documento significativo para entendermos o ensino de Química neste entorno lavoisierano na Europa, e mais especificamente em Portugal, temos que considerar que o mesmo é produto da Reforma da Universidade de Coimbra... (CHASSOT, 1994, p. 76). 
Tendo estes aspectos como norte, salientamos a necessidade de análise deste documento para compreensão, sob perspectiva histórica, do modus operandi da disciplina de Química, contemplando concepções acerca dos objetivos, metodologias e conteúdos trabalhados. E é no Capítulo IV do Estatuto da Faculdade de Filosofia de Coimbra onde encontramos a parte que trata da Química. Sua estrutura é constituída por quatorze diretrizes, que deveriam ser empregadas pelo professor no exercício de sua função, descrevendo conteúdos programáticos, estratégias e instrumentos, assim como algumas metodologias aplicáveis ao ensino de conteúdos referentes à Química. Sublinhamos que o teor desta fonte permite afirmar sobre a existência de um caráter disciplinar da Química, no sentido de uma dinâmica histórica de evolução entre ensinamentos disciplinares e científicos, que configura limiares no estudo da história das disciplinas escolares, nos quais consideramos a gênese e o funcionamento de uma dada disciplina (cf. CHERVEL, 1990, p.186).

Mediante os procedimentos previstos na Análise de Conteúdo, principiamos pela leitura flutuante do Estatuto. Após repetidas leituras de cada uma das diretrizes, destacamos palavras-chave que se relacionam com o desenvolvimento dinâmico da Química; quer dizer, tais termos foram categorizados e analisados no contexto da escrita que emana o teor e as finalidades constituintes da disciplina. Por exemplo: o termo substância tem relação direta com os estudos químicos, sendo inserido em um contexto que justifica o seu estudo, além de apresentar-se como um conteúdo básico e importante para a base científica associada. Por fim, após as etapas intermediárias já descritas, alcançamos a etapa da categorização final.

A primeira categoria resultante, identificada como objetivos, engloba palavras correspondentes às orientações dadas ao professor para a seleção de conteúdos e a escolha de estratégias de ensino (GIL, 2011, p. 43). Como componentes desta categoria, destacamos os objetivos para o ensino da Química no novo Curso de Filosofia da Universidade de Coimbra. Palavras-chave como estudar, examinar, separar, apresentar e explicar se destacam, pela quantidade de ocorrências, entre outras que também apontam para os objetivos. Dado o caráter oficial dos Estatutos, a categoria objetivos permite estimar as relações entre o texto analisado e as finalidades do ensino, mesmo que não haja uma correspondência explicitamente formulada (cf. CHERVEL, 1990, p.188-9).

A segunda categoria é denominada de conteúdos e incorpora os termos mais citados que fazem referência aos conteúdos e campos de estudo explorados na Reforma realizada em Coimbra. Consideramos os principais: corpos, substância, composição, História da Ciência, afinidade, propriedade. Dela emergiu uma subcategoria, que chamamos de conteúdos específicos, agregando as palavras sais, ácidos, água, bases, metais, óleos. A assunção desta categoria vai ao encontro da afirmação de Chervel (1990, p.219), segundo a qual a história das disciplinas escolares "[...] colocando os conteúdos de ensino no centro de suas preocupações, renova as problemáticas tradicionais". Neste sentido, se confere centralidade ao processo de criação das disciplinas, relacionado às transformações históricas por que passa a escola.

Já a terceira categoria, metodologia, é determinada pela relação objetivo-conteúdo, que expõe mecanismos para o alcance dos objetivos (LIBÂNEO, 1994, p. 149). Neste caso, a codificação foi mais complexa, pois quando tratamos de metodologia temos uma via de mão dupla entre os objetivos e os conteúdos. Além disto, como problematiza Chervel (1990, p.194), há que se considerar "[...] a liberdade teórica de criação disciplinar do mestre que se exerce em um lugar e sobre um público igualmente bem determinados [...]. As condições materiais nas quais se dá o ensino estão estreitamente ligadas aos conteúdos disciplinares". Este conjunto é definido através dos termos lente/professor, teoria, experiência/prática/laboratório. 
Organizamos um quadro que expõe as categorias criadas, os termos que as informam, a frequência de ocorrência e a diretriz em que está presente.

Quadro 1 - Termos referentes às três categorias, Objetivos, Conteúdos e Metodologia, sua ocorrência e diretriz em que está localizada no Estatuto da Faculdade de Filosofia de Coimbra.

\begin{tabular}{|c|c|c|c|}
\hline CATEGORIAS & TERMO & OCORRÊNCIA & DIRETRIZ \\
\hline \multirow{5}{*}{ Objetivos } & Estudar & 1 & I \\
\hline & Examinar & 2 & II \\
\hline & Separar & 1 & II \\
\hline & Apresentar & 3 & III, XIII, XIV \\
\hline & Explicar & 7 & $\begin{array}{l}\text { I, IV, V, VII, VIII(2x), } \\
\text { XI. }\end{array}$ \\
\hline \multirow[t]{6}{*}{ Conteúdo } & Corpos & 13 & $\begin{array}{l}\mathrm{I}(2 \mathrm{x}), \quad \mathrm{II}, \quad \mathrm{IV}(3 \mathrm{x}), \\
\mathrm{V}(3 \mathrm{x}), \mathrm{VI}, \mathrm{VII}(3 \mathrm{x})\end{array}$ \\
\hline & Substância & 13 & $\begin{array}{l}\mathrm{II}(2 \mathrm{x}), \quad \mathrm{IV}, \quad \mathrm{V}, \quad \mathrm{VI}, \\
\mathrm{VII}(2 \mathrm{x}), \\
\mathrm{IX}(2 \mathrm{x}), \mathrm{X}(2 \mathrm{x})\end{array}$ \\
\hline & Composição & 4 & II, IV, V, VII \\
\hline & História da Ciência & 1 & III \\
\hline & Afinidade & 7 & $\mathrm{~V}, \mathrm{VI}(2 \mathrm{x}), \mathrm{VII}(3 \mathrm{x}), \mathrm{XI}$ \\
\hline & Propriedade & 4 & II, V, VIII, X \\
\hline \multicolumn{4}{|l|}{ SUBCATEGORIA } \\
\hline \multirow[t]{6}{*}{ Conteúdos Específicos } & Sais & 2 & $\operatorname{VIII}(2 X)$ \\
\hline & Ácidos & 3 & VIII(2X), X \\
\hline & Água & 1 & VIII \\
\hline & Bases & 1 & VIII \\
\hline & Metais & 2 & $\mathrm{IX}(2 \mathrm{X})$ \\
\hline & Óleos & 2 & $\mathrm{X}(2 \mathrm{X})$ \\
\hline \multicolumn{4}{|l|}{ CATEGORIA } \\
\hline \multirow[t]{3}{*}{ Metodologia } & Lente/professor & $4 / 2$ & $\begin{array}{l}\text { III, VII, XIV(2X) / IV, } \\
\text { XII }\end{array}$ \\
\hline & Teoria & 2 & XI, XII \\
\hline & $\begin{array}{l}\text { Experiência/Prática/ } \\
\text { Laboratório }\end{array}$ & $\begin{array}{l}7 / 2 / \\
1\end{array}$ & $\begin{array}{l}\text { IV, VI(2X), VIII, IX, } \\
\text { XI, XIII / XII, XIII / } \\
\text { XIII }\end{array}$ \\
\hline
\end{tabular}

Fonte: Elaborado pelos autores.

Considerando a relação entre o novo Estatuto da Faculdade de Filosofia e a Reforma da Universidade de Coimbra, para efeito de uma composição analítico-interpretativa mais ampla, acrescentamos referências ao quarto capítulo do Livro III dos Estatutos da Universidade, onde está o rol de diretrizes. Sua redação começa assim:

Capítulo IV

Das Lições do Quarto Anno

I- Tendo no Anno precedente aprendido os Estudantes Filosofos as verdades de facto, que o Magisterio da Experiencia tem mostrado nos 
Corpos, considerados como massas homogeneas; e aplicados mecanicamente a obrar huns sobre os outros: Passarão no quarto anno a estudar as verdades, que a mesma Experiencia tem mostrado sobre as partes, de que se compõem os mesmos Corpos; e sobre os Fenomenos, que resultam da applicação íntima, e contacto das mesmas partes; Fenomenos, que se não podem explicar pelas Leis ordinarias da Mecanica; e que constituem huma Sciencia á parte. (ESTATUTOS DA UNIVERSIDADE DE COIMBRA, 1772, p. 387-88, grifos nossos).

Portanto, era a partir do quarto ano que se iniciavam os estudos da Química na Faculdade de Filosofia. Chassot (1994, p.77) afirma que: "Nas diretrizes [...] transcritas, os alunos do Curso de Filosofia já haviam estudado no ano anterior Matemática e Física (e nesta particularmente a Mecânica), agora são apresentados a uma nova Ciência".

Esta nova ciência é apresentada com o objetivo de se estudar a veracidade e a constituição das partes de um corpo. Caracterizam-na como possuidora de autenticidade e exatidão de conhecimentos a respeito da interação dos corpos, superando as leis até então existentes. Em particular, chegava para agregar entendimentos a um dos principais conteúdos expostos no Estatuto, o estudo sobre os corpos.

Ao analisar a segunda diretriz, extraímos a importância e a necessidade de inserção dessa nova ciência, que iria beneficiar o estudo de interação entre os elementos que compõem as substâncias: a Química.

II - Essa Sciencia tem o nome de Chymica, e he a Terceira Parte da Filosofia Natural. Nella se ensina a separar as diferentes substancias, que entram na Composição de um Corpo; a examinar cada uma das suas partes; a indagar as propriedades, e analogia dellas; a comparallas, e combinallas com outras substancias; e a produzir por mixturas diferentemente combinadas novos Compostos, de que na mesma Natureza se não acha modello, nem exemplo. (ESTATUTOS DA UNIVERSIDADE DE COIMBRA, 1772, p. 388, grifos nossos).

Entendemos que em relação à categoria objetivos esta diretriz é clara. Explica que o ensino da Química tem os seguintes objetivos: separar, examinar e produzir novos compostos com base em outros; ou seja, reforça aquilo que foi dito na primeira diretriz. Neste caso, com base na categoria conteúdos, observamos uma inserção que se justifica com o tratamento das diferentes substâncias, sua composição e propriedades. Evidencia-se que essas substâncias estão sujeitas a misturas, rearranjos e à formação de novos compostos iniciando da interação de suas partes.

$\mathrm{Na}$ diretriz II a Química é caracterizada: Ciência que possibilitaria a separação das diferentes substâncias, utilizando técnicas químicas, permitiria organizar, compilar e produzir novos compostos não encontrados na natureza (ESTATUTOS DA UNIVERSIDADE DE COIMBRA, 1772, p. 388). Segundo Chassot (1994, p.78), uma das questões que chama a atenção é a não utilização do conceito de elemento químico, embora este já houvesse sido proposto por Robert Boyle em seu livro O Químico Cético, publicado no ano de 1661, ou seja, mais de um século antes da publicação do Estatuto. Atentemos, a seguir, para a terceira diretriz:

III - Porém antes de nas Lições desta Sciencia, dará o Lente hum Resumo abreviado da Historia della: Mostrando a origem que teve; os progressos que fez; as revoluções; os sucessos: a decadencia; e o descredito, em que esteve pelos mysterios obscuros dos Alchymistas, e pelas pretensões frivolas da Pedra filosofal, e outros segredos, cuja 
invenção se propunham homens de maior temeridade, que prudencia: E expondo mais circunstanciadamente a restauração desta Sciencia nestes ultimos tempos; e as utilidades, que tem produzido nas Artes, que della dependem. (ESTATUTOS DA UNIVERSIDADE DE COIMBRA, 1772, p. 388-89, grifos nossos).

Com a diretriz III é iniciada uma orientação metodológica e de conteúdo dirigida ao lente. Também tinha como objetivo apresentar aos alunos questões referentes à história da Química. Entendia-se que era necessário um conhecimento sobre os primórdios da Química, como ela vinha se constituindo, as disputas intelectuais em torno do saber e, principalmente, sua evolução no campo científico. Havia uma preocupação em relação à distinção entre os alquimistas e os químicos, já que os primeiros eram considerados enganadores e não correspondiam aos novos rumos da ciência. $\mathrm{Na}$ visão dos autores do Estatuto, se buscava romper com algumas barreiras presentes no ensino das ciências. Em outras palavras, superar obstáculos que punham em evidência a disputa entre um ensino científico e um ensino de caráter humanista.

A diretriz de número IV apresenta limitações e barreiras para o estudo da Química e evidencia o papel do professor como principal agente formulador de soluções.

IV - Como a da Analyse, e da Composição dos Corpos he limitada; e senão póde promover, senão até certo ponto; parando-se finalmente nas barreiras de certas substancias inalteraveis a toda a força do Artificio Chymico; estas relativamente ao nosso uso se podem, e devem tomar como Principios, e elementos dos Corpos. E sobre estes explicará o Professor tudo o que tem resultado da combinação das experiencias Chymicas; sem pretender com tudo averiguar a natureza de cada um dos elementos simplices de que os Corpos se compõem; substituindo as imaginações, onde falta, as experiencias. (ESTATUTOS DA UNIVERSIDADE DE COIMBRA, 1772, p. 389, grifos nossos).

Quanto ao teor acima, as limitações existentes deveriam ser consideradas; os conceitos, conhecimentos e técnicas químicas não iriam solucionar todas as questões. Com isso, caberia ao professor o objetivo de explicar quais resultados seriam originados do experimentalismo. Nesse caso, experiência química se encaixa na categoria metodologia, sendo também denominada Artifícios Químicos, apresentando conceitos a respeito da composição dos corpos e de sua interação. Pondera-se que quando esgotadas tais possibilidades e artifícios, se deve levar em conta a característica do corpo em estudo. Contudo, é papel do professor não divagar ou criar conjecturas sobre conhecimentos ainda não fundamentados, pois cometeria o erro de apresentar aspectos provenientes da escolástica medieval, já depreciada.

Além desse fato, evidenciamos o conteúdo geral referente aos corpos, pois como nas três primeiras diretrizes, este seria o foco dos estudos da Química, uma matriz para o desenvolvimento de outros conteúdos. O que chama atenção é a busca pela comprovação das teorias estudadas pautada na realização de experimentos, bem como o papel primordial do professor no que diz respeito à explicação de cada acontecimento. A diretriz IV apresenta características de um distanciamento em relação aos estudos humanistas, pois busca através de experiências comprovar leis e apresentar limitações do conhecimento, provenientes de atributos dos corpos ainda não conhecidos. 
A quinta diretriz inicia apresentando um objetivo geral, que significa uma explicação dos conteúdos referentes às propriedades das substâncias e sua inserção na composição dos corpos, sendo esse objeto de estudo particular da Química. É nesta diretriz que surge o conceito de afinidade, que consideramos também como conteúdo.

V - Depois disto dará huma idéa geral das propriedades relativas das substancias, que entram na composição dos Corpos, e pertencem ao objecto particular da Chymica: Porque assim como na Physica se explicam os factos, que resultam da atracção e impulsão dos Corpos, considerados huns fora dos outros; do mesmo modo na Chymica se consideram os factos, que resultam da intima união dos mesmos Corpos, á qual em termos da Arte se tem dado o nome de Affinidade. (ESTATUTOS DA UNIVERSIDADE DE COIMBRA, 1772, p. 389-90, grifos nossos).

Outrossim, o termo afinidade é citado sete vezes ao longo das quatorze diretrizes, principalmente nas de número VI e VII, o que evidencia sua importância. Vejamos:

VI - Com efeito todas as experiências concorrem a provar, que entre os diferentes corpos, tanto simpleces como compostos, ha huma certa conveniencia, relação, ou affinidade, em razão da qual algumas das ditas substancias se unem intimamente entre si; ao mesmo tempo que repugnam a contrair união com as outras. Este effeito geral (seja qual for a sua causa) he o que se chama Affinidade; e tem o mesmo lugar na Chymica, que a Gravitação Universal no Mechanismo do Universo; servindo não somente de dar razão de todos os Fenomenos particulares, mas tambem de os ligar em hum Systema de Doutrina. (ESTATUTOS DA UNIVERSIDADE DE COIMBRA, 1772, p. 390, grifos nossos).

E na diretriz seguinte:

VII - Pelo que, mostrará o Lente em primeiro lugar as verdades fundamentaes, que se tem provado decisivamente ácerca da Affinidade dos Corpos; como por exemplo: Que se ha um Composto de duas substancias se applica hum terceiro Corpo, que não tenha affinidade com huma dellas; e que tenha com a outra, maior do que ellas ambas entre si, resulta necessariamente huma decomposição, e huma nova união; isto he, que o terceiro Corpo separa as duas substancias huma da outra, e se une com aquela, com a qual tem affinidade; formando com ella um novo composto, e deixando a outra livre, e desembaraçada, como ela era antes de haver contrahido a união. Semelhantes a estes são outros factos geraes, que se devem explicar, antes de entrar no exame dos particulares. (ESTATUTOS DA UNIVERSIDADE DE COIMBRA, 1772, p. 390-91, grifos nossos).

A diretriz VI traz novamente como conteúdo o estudo dos corpos e das substâncias. No entanto, reapresenta o conceito de afinidade, o qual categorizamos como conteúdo geral. Lembramos que a afinidade é definida como a razão para a união das substâncias. E este conceito é apresentado, até os dias de hoje, como basilar para o desenvolvimento do estudo da Química. Além disso, serve "não sómente de dar razão de todos os Fenomenos particulares, mas tambem de os ligar em hum Systema de Doutrina" (ESTATUTOS DA UNIVERSIDADE DE COIMBRA, 1772, p. 390). 
Faz parte da categoria objetivo, na diretriz VII, o termo mostrar, que neste caso entendemos colocado no sentido de explicar e apresentar as verdades fundamentais do estudo da Química, partindo do princípio da afinidade. Nesta escrita ele é explorado, sendo, como nas outras diretrizes, essencial para conteúdos que tratam das substâncias. A combinação entre duas substâncias que resultaria em uma terceira e qual o grau dessa união seriam explorados e explicados através das afinidades. Isto é considerado um fato geral, comum nas reações químicas e antecede acertadamente os conceitos abordados na diretriz de número VIII.

Além disso, destacamos como a figura do docente é permanente ao longo das diretrizes. E na diretriz de número VII não é diferente. Esta também apresenta um roteiro metodológico, bem detalhado, que traça o modo pelo qual o conteúdo deve ser seguido e abordado pelo professor. A análise que segue corrobora com nossa análise.

Talvez o mais significativo neste parágrafo não sejam as dificuldades conceituais do autor, por não usar ainda o termo molécula e assim não poder explicar com clareza a formação de novas substâncias, chegando passar a idéia que elementos ficassem livres, mas o que impressiona é como em um texto que tem como título Estatuto, se detalha de uma maneira tão precisa o que o professor deve explicar sobre a importante afinidade. (CHASSOT, 1994, p. 82).

Ainda sobre o conceito de afinidade, sua difusão dentro da Química ocorreu em meados do século XVIII. No entanto, perdeu força após a publicação da obra de Lavoisier, Traitè Élémentaire, no ano de 1789. Deste modo, fica evidente que a abordagem da afinidade trazida nas diretrizes do Estatuto da Faculdade de Filosofia de Coimbra é tida como básica para o aprofundamento de estudos da Química e sua constituição como disciplina. Sua principal definição é sobre uma interação entre os corpos, formação de novos compostos e decomposição de outros. Abordamos agora a diretriz número VIII.

VIII - Tendo explicado os principios geraes, ou os factos generalizados, pela combinação das experiencias; entrará no exame das substancias, que constituem espécies particulares, começando sempre pelas mais simplices, e passando delas as mais compostas. Assim principiará pelas substancias salinas em geral, e particular; mostrando as propriedades, e afinidades dos acidos com as Terras adsorventes, com a Agua, e com o Flogistico; e explicando as particulares observações dos Alkalis fixos e volateis; dos saes neutros; dos ácidos vitriolicos, nitrosos, etc. (ESTATUTOS DA UNIVERSIDADE DE COIMBRA, 1772, p. 391, grifos nossos).

Como objetivo a diretriz apresenta a explicação dos princípios gerais ensinados até aquele ponto. Com uma metodologia sustentada nas experiências já elencadas, o professor deveria abordar os conceitos sobre as substâncias, partindo das mais simples até as mais complexas. Com base nisto, segue-se uma ordenação de conteúdos específicos, iniciando-se com o estudo dos sais e ácidos e suas possíveis afinidades com a terra, a água e o flogisto ${ }^{1}$. Chassot (1994, p.82) chama atenção para uma situação:

\footnotetext{
1 A teoria do flogisto (ou do flogístico) foi desenvolvida pelo químico e médico alemão Georg Ernst Stahl entre 1703 e 1731. Segundo Stahl os corpos combustíveis possuiriam uma matéria chamada flogisto, liberada ao ar durante os processos de combustão (de material orgânico) ou de calcinação (de metais).
} 
[...] neste parágrafo ganha um significado histórico especial, pois já em 1774, apenas dois anos depois que o Estatuto fora publicado, Lavoisier, pressentindo que a Teoria do Flogisto, estabelecida pelo médico alemão G. E. Stahl (1660-1734) fundamentava-se em uma hipótese errônea, busca novas explicações e apresenta, com sucesso os resultados de suas programadas experiências de combustão.

Após o estudo destas substâncias ditas mais simples, teria início o estudo das bases tratadas no Estatuto como Alkalis - e o estudo dos ácidos, ali representados pelos ácidos vitriolicos, que são denominados pela nomenclatura moderna de ácidos sulfúricos. Portanto, nesta diretriz se insere um conjunto de conteúdos específicos para o estudo da Química, que têm como base os conceitos previamente ensinados, como afinidade e propriedade dos corpos.

A Diretriz IX ressalta a importância de se estudar conteúdos voltados aos metais. O objetivo de estudá-los consiste em um aperfeiçoamento de técnicas já utilizadas para sua extração e beneficiamento, tanto em Portugal quanto no Brasil Colônia. Portanto, fatores históricos contextuais de base econômica estão intimamente relacionados às finalidades da disciplina de Química.

IX - Dahi passará ás substancias metalicas em geral, e particular; mostrando o resultado das Experiencias, que se tem feito sobre o ouro, prata, cobre, estanho, chumbo, mercurio, regulo de antimonio, etc; sobre o que não se esquecerá de factos mais importantes, que dizem relação ao uso das Artes, que trabalham na manipulação das ditas substancias metalicas; como são meios de procurar-lhes facilmente a fusão, dissolução, separação, amalgamação, etc. (ESTATUTOS DA UNIVERSIDADE DE COIMBRA, 1772, p. 391-92, grifos nossos).

Agora, aborda-se uma área proveniente da então desacreditada alquimia. O estudo dos metais foi instituído e organizado como um dos primeiros estudos de caráter científico, principalmente, no que diz respeito à exploração mineral. Segundo o texto, o professor deveria tratar o conteúdo metais, primeiramente apresentando as principais substâncias metálicas como ouro, prata, cobre, estanho, chumbo e mercúrio; depois, apresentando suas fusões, dissoluções e separações. Estes metais eram, em sua maioria, utilizados como moeda de troca e na cunhagem de armas. Logo, fica evidente a necessidade de se conhecer as técnicas e procedimentos químicos utilizados para o beneficiamento dos metais. Esse fato afirma a preocupação dos governantes portugueses no que diz respeito a um desenvolvimento econômico baseado no progresso científico. E aqui se avança no sentido de dizer, acompanhando a terminologia cunhada por Chervel (1990, p.190), das novas finalidades de objetivo e reais que a disciplina de Química vai incorporando ao longo de sua história.

A diretriz de número $\mathrm{X}$ apresenta o início dos estudos voltados a um conjunto de conteúdos químicos que futuramente estariam inseridos na constituição e desenvolvimento da atual Química Orgânica.

$\mathrm{X}$ - Depois disto passará ás substancias oleosas em geral, e particular; tratando dos oleos mineraes, vegetaes, e animaes; das preparações, e do uso delles. Donde se encaminhará para a fermentação em geral, e para as especies particulares dela: Examinando as diferentes propriedades, e phenomenos das fermentações espirituosas, acidas, e putridas: Ajuntando as reflexões necessarias sobre os meios, e operações, que se empregam na 
analyse das substancias animaes, vegetaes, e mineraes, como são as distilações, emulsões, dissoluções, etc. (ESTATUTOS DA UNIVERSIDADE DE COIMBRA, 1772, p. 392, grifos nossos).

Os objetivos demonstram uma finalidade da parte teórica da Química. O professor tem então o propósito de ensinar um conteúdo relacionado às substâncias oleosas. A abordagem deste teor seria iniciada com a apresentação das propriedades dos óleos animais, vegetais e minerais e se encerraria com a identificação de métodos e técnicas que separem, unam ou dissolvam esses óleos. Segundo Fonseca (2013), são encontrados óleos animais como o de capivara e o de fígado de bacalhau, mas também óleos vegetais, de que são exemplos conhecidos os de oliva, de soja e de girassol.

Para encerrar a parte teórica da Química, a diretriz de número XI apresenta como objetivo a inserção de uma ferramenta de ensino que auxiliará professor e alunos no ensino e aprendizagem da Química: a Tábua de Afinidades.

XI - E acabará a parte Theorica desta Sciencia, explicando a Taboa de Affinidades, em que se acham artificiosamente recapituladas as verdades fundamentaes da Arte, que no curso das lições se mostram pelo resultado das Experiencias. Não dissimulará porém os defeitos, e imperfeições, que nela se acham até o presente. Antes mostrará (se possível for) os meios de a fazer cada vez mais perfeita e completa. (ESTATUTOS DA UNIVERSIDADE DE COIMBRA, 1772, p. 392-393, grifos nossos).

Cabe retomar elementos já descritos sobre o conceito de afinidades, tratados nas diretrizes do Estatuto da Faculdade de Filosofia de Coimbra. Sua principal definição se refere a uma interação entre os corpos, à formação de novos compostos e à decomposição de outros.

A partir da diretriz de número XII tem início a parte prática referente aos conteúdos de Química. Segundo esta, elementos práticos são complementos no desenvolvimento das aulas teóricas e se constituem como fatores do ensino da disciplina que facilitam a compreensão das lições teóricas. A segmentação entre teoria e prática é evidente.

XII - Como as Lições Theoricas nesta Sciencia não podem ser bem comprehendidas, sem a pratica dellas; deverá o Professor mostrar aos seus Discipulos todos os Processos Chymicos, que são conhecidos na Arte: Tratando da Analyse, e das operações sobre os differentes productos dos tres Reinos da Natureza. Não se limitando á escolha dos Processos relativos ao uso de alguma arte particular: E extendendo a vista sobre todas as que dependem da Chimica geral, e Philosofica. (ESTATUTOS DA UNIVERSIDADE DE COIMBRA, 1772, p. 393, grifos nossos).

É possível comparar essa dissociação entre parte teórica e prática com uma perspectiva educacional, a clássica. Nesta situação, o domínio do professor e uma excessiva ênfase nos tópicos a serem ensinados dentro da sala de aula definem o aluno como ser passivo no processo de ensino. Concordamos com Gil (2011, p.24) que, com isto, os professores se vêem, ao final desta primeira parte doutrinal, como personagens que controlam a exposição dos fatos ensinados. Convergimos ainda, nesta análise, com a afirmativa de Chervel (1990, p.202) quanto aos constituintes de uma disciplina escolar: "Dos diversos componentes de uma disciplina escolar, o primeiro na ordem cronológica, senão na ordem de importância, é a exposição pelo professor ou pelo manual de um conteúdo de conhecimentos". E como 
exposto naquelas diretrizes, a primeira parte do ensino de Química na Faculdade de Filosofia de Coimbra era dirigida apenas a uma constituinte teórica, principalmente no que diz respeito ao papel dos alunos. Logo, a atribuição do trabalho docente era a utilização de aulas de caráter expositivo, compostas com base em objetivos que visavam a transmissão de saber.

Porém, seria também um escopo do professor ensinar aos seus alunos o maior número possível de processos químicos práticos, que envolviam não apenas um conteúdo específico, mas sim englobando tudo aquilo que está ao alcance do homem como objeto de estudo. Nesse sentido, os três reinos da natureza deveriam ser explorados para a realização dessa tarefa metodológica e transmissora.

A diretriz de número XIII não difere muito da décima segunda. Tinha-se como objetivo elevar o apreço dos alunos por esta ciência, além de contribuir para o seu desenvolvimento através de fatos concretos e conclusões que têm como base a Química prática. Era objetivo do professor incentivar e apoiar os alunos na participação das aulas práticas e, como conteúdo destas, explorar tudo aquilo que havia sido estudado até o momento. Sublinhamos a presença do laboratório - lugar das experiências - como ambiente formativo nuclear para a disciplina ser desenvolvida.

XIII - Para isso dará as Lições de competentes de Prática no Laboratorio; nas quais não fará de seus discipulos meros espectadores; mas sim os obrigará a trabalhar nas mesmas Experiencias, para se formarem no gosto de observar a Natureza; e de contribuirem por si mesmos ao adiantamento, e progresso desta Sciencia. A qual não se enriquece com Systemas vãos, e especulações ociosas, mas com descobrimentos reaes, que não se acham de outro modo, senão observando, experimentando, e trabalhando. (ESTATUTOS DA UNIVERSIDADE DE COIMBRA, 1772, p. 393, grifos nossos).

Neste sentido, sublinhamos a perspectiva analítica segundo a qual caberia agora aos alunos se envolverem com a perspectiva experimental, assumindo postura ativa no processo:

A ênfase a experimentação vai além da demonstração de cátedra, que oferecia muita oportunidade para brilhaturas, herdadas da Universidade medieval e ainda então, muito ao gosto. Há a recomendação muito explícita de que os alunos não sejam expectadores, mas manipuladores, para que sim se afeiçoem a experimentar e não fiquem no especular ocioso. (CHASSOT, 1994, p. 85).

A diretriz XIV encerra a análise. Nesta é outra vez caracterizado o papel do professor no decorrer das aulas. $\mathrm{O}$ docente teria como obrigação ser exemplo de trabalho e dedicação para os alunos. Mais que isto, seus ensinamentos deveriam condizer com a evolução que perpassava a ciência. A rescisão com os ensinamentos e preceitos escolásticos era solicitada, tendo como alvo a busca por um progresso no tratamento e estudo dos conhecimentos científicos.

XIV - O Lente será por isso obrigado a dar por si mesmo aos seus discípulos exemplo do trabalho, e constancia, que se requerem no Observatorio da Natureza: Desabusando-os das idéas insensatas dos Escolasticos, que punham a sua gloria em fabricar mundos chimericos no vazio de suas imaginações: e em ignorar o nome, e riqueza do Mundo actual, que Deos creou para uso, e contemplação do Homem. E faltando esta parte essencial da sua obrigação, (o que não Espero) 
ficará sujeito aos que tenho disposto a respeito dos Medicos na Primeira Parte deste Livro, Titulo Terceiro, Capitulo Primeiro, Paragrafos Trinta e hum, e Trinta e dous. Disposição, que igualmente se entenderá a respeito de outros Lentes, se faltarem do mesmo modo, no que pertencer á prática nas suas respectivas Lições. (ESTATUTOS DA UNIVERSIDADE DE COIMBRA, 1772, p. 393-94, grifos nossos)

Após analisar as quatorze diretrizes organizadas para o desenvolvimento das atividades pedagógicas na nova Faculdade de Filosofia de Coimbra, nas quais estava inserida a disciplina de Química, verificamos um padrão na escrita, com normas bem redigidas e detalhadas no que diz respeito ao ensino. Por se tratar de documento orientador para o desenvolvimento do trabalho dos conteúdos químicos, era expressamente dirigido aos docentes que conduziriam as aulas.

Foram abordadas questões de objetivo, de conteúdo e metodológicas, as quais estavam em consonância com a Reforma por que a Universidade passava. Mesmo diante do fato de que, em alguns trechos, não existia uma atualização no que diz respeito aos avanços de estudos químicos, como vimos na referência à Teoria do Flogisto. Por outro lado, há a apresentação de conceitos utilizados e abordados posteriormente por Lavoisier ${ }^{2}$, o que indica uma evidente efetivação dos objetivos propostos pela Reforma da Universidade de Coimbra, com a fuga de um ensino com caráter humanista e a elaboração da oferta de uma disciplina baseada em teorias e conceitos científicos emergentes, posteriormente reafirmados.

\section{Considerações finais}

Retomamos os referenciais teórico-metodológicos utilizados para nossas análises e interpretações, de modo a revigorar a carga conceitual inserida na textualidade da fonte utilizada. Adotamos o procedimento metodológico da Análise de Conteúdo, proposto por Bardin (2004). As etapas do processo, em suas vertentes quantitativas e qualitativas, auxiliaram no encontro de palavras referentes a aspectos da história da disciplina de Química e que se prestaram à categorização. Já no repertório teórico de Chervel (1990) localizamos os aspectos referentes à disciplina escolar que desafiam os pesquisadores, já que se trata de um conceito historicamente elaborado e em movimento.

Com base na análise do Estatuto da Faculdade de Filosofia de Coimbra, foi possível responder algumas das questões levantadas por Chervel, aplicando-as aos nossos questionamentos quanto à gênese da disciplina escolar de Química. Quanto às finalidades associadas à configuração da disciplina entranhadas no âmbito da Reforma, além de atender a interesses econômicos, a sua criação e inserção na Universidade de Coimbra trouxe efeitos de mudança. Por meio da Análise de Conteúdo foi possível verificar a importância dada à disciplina de Química, pois a Faculdade de Filosofia apresentava disciplinas que aproximavam dos estudos científicos, ignorados pelos jesuítas. A mudança no caráter pedagógico e educacional é condizente com os novos anseios políticos e sociais portugueses baseados em ideias iluministas. Notadamente, ilustra a passagem do ensino humanista para o científico. Ou seja, a disciplina foi criada com objetivo e função de alavancar estudos científicos, algo que beneficiaria o desenvolvimento humano. Com base no Estatuto, a Química serviria como um dos carros chefe para esta mudança.

Identificamos no Estatuto da Faculdade de Filosofia de Coimbra quatorze diretrizes para o ensino da Química, dirigidas ao professor. Da Análise de Conteúdo aplicada emergiram três categorias: objetivos, conteúdos e metodologia.

\footnotetext{
${ }^{2}$ Lavoisier (1743-1794) era conhecido por observações cuidadosas e pelo planejamento metódico de seus experimentos, sendo por isto considerado um dos fundadores da Química Moderna.
} 
Quanto à categoria objetivos, engloba os termos que se referem a orientações dadas ao professor sobre a seleção de conteúdos e estratégias de ensino e as palavras-chave mais frequentes que a constituem são estudar, examinar, separar, apresentar e explicar.

Incorporando termos que fazem referência aos conteúdos e campos de estudo explorados, a categoria conteúdos é delineada pelos termos corpos, substância, composição, História da Ciência, afinidade, propriedade, combinação, misturas e comparação. Esta categoria permitiu, ainda, o registro de termos que implicaram o delinear de conteúdos específicos diretamente vinculados à disciplina, tais como sais, ácidos, água, bases, metais e óleos.

A terceira categoria, metodologia, é um fator determinado pela relação objetivoconteúdo que expõe mecanismos para o alcance dos objetivos. Neste caso, a terminologia constitutiva apresenta os termos lente/professor, teoria e experiência/prática/laboratório.

Considerado o conjunto categorial, foi possível delinear algumas conclusões com base no teor das diretrizes, as quais estabelecem relações sobre a importância dos estudos da disciplina de Química naquele contexto histórico, permitindo verificar tanto a existência de conteúdos seminais quanto de outros que seriam futuramente validados. Por exemplo, a utilização do termo corpo, enquanto sinônimo de substância, serve como ponto de partida para o estudo desta nova ciência. No devir histórico, este conteúdo funcionou como base para o desenvolvimento de outros conteúdos químicos, partindo de sua composição e possíveis combinações, vindo a apresentar a seguinte classificação: líquida, sólida, mole e dura.

A respeito do funcionamento da Química enquanto disciplina, observamos que as diretrizes são detalhadas, tratando sobre o trabalho do professor e dos conteúdos a serem abordados, assim como de uma proposta de metodologia de ensino. Neste caso, se relata quanto às aulas teóricas e práticas, distinguindo-as, porém não se aprofundando em como seriam desenvolvidas de acordo com essa natureza bipartida. No entanto, ao questionar sobre os procedimentos utilizados, encontramos referências ao método sintético demonstrativo, no qual o professor era responsável pela compressão do conteúdo, de forma que pudesse ser abordado de forma sistemática. Neste caso, partiria do simples para o complexo.

Por fim, reafirmamos que o procedimento analítico utilizado auxiliou no estabelecimento de alguns dos fatores presentes nos primórdios da disciplina escolar de Química. Cabe destacar ainda que, na continuidade de nossos estudos, acompanhamos o posterior processo de circulação da disciplina da Química, com sua chegada ao Brasil. Neste caso, considerando fatores como a irradiação da influência dos ditames estatutários para o ensino da disciplina presentes no Estatuto da Faculdade de Filosofia de Coimbra, do retorno ao território brasileiro de brasileiros que foram estudar Química na instituição coimbrense e da escrita de livros e compêndios da disciplina que foram utilizados em instituições de ensino secundário e superior.

A partir deste momento, a Química prossegue seu caminho enquanto disciplina escolar, colaborando, conforme ratifica Chervel (1990, p.220), como um dos elementos motores da escolarização, preparando a aculturação dos alunos em conformidade com certas finalidades, o que vem a explicar sua gênese e leva à constituição de sua razão social. Absolutamente em sintonia com a modernidade emergente, a Química não apenas se fortalecerá como ciência de referência, mas encontrará seu lugar na escola para, num movimento concomitante e dinâmico, transpor os muros da escola e, novamente, penetrar na sociedade.

\section{Referências}

BARDIN, L. Análise de conteúdo. Lisboa: Edições 70, 2004.

CARDOSO, T.F.L. As aulas régias no Brasil. In: In: STEPHANOU, M; CÂMARA BASTOS, M.H. (Orgs.) Histórias e Memórias da Educação no Brasil. Petrópolis: Vozes. 2004. v.I, p.179-191. 
CHASSOT, A. Para que(m) é útil o nosso ensino de Química? 1994. 316 f. Tese (Doutorado em Educação) - PPGE. Universidade Federal do Rio Grande do Sul, Porto Alegre, 1994.

CHERVEL, A. História das disciplinas escolares: reflexões sobre um campo de pesquisa. Teoria \& Educação, Porto Alegre, n.2, 1990, p. 177-229.

FONSECA, M. R. M. Química. São Paulo: Ática, 2013.

GAUER, R. M. C. A modernidade portuguesa e a reforma pombalina de 1772 . Porto Alegre: EDIPUCRS, 1996.

GIL, A. C. Metodologia do ensino superior. São Paulo: Atlas, 2011.

LIBÂNEO, J. C. Didática. São Paulo: Cortez, 1994.

NUNES, C. T. F. M. Os Estatutos de 1772 da Universidade de Coimbra. In: VI Congresso Brasileiro de História da Educação, VI. Anais. Vitória, 2011. Disponível em: <www.sbhe.org.br/novo/congressos/cbhe6>/anais_vi_cbhe/conteudo/file/1405.doc+\&cd=2\& $\mathrm{hl}=\mathrm{pt}-\mathrm{BR} \& \mathrm{ct}=\mathrm{clnk} \& \mathrm{gl}=\mathrm{BR}>$. Acesso em: 19 maio 2017.

SAVIANI, D. História das ideias pedagógicas no Brasil. Campinas, SP: Autores Associados, 2011. 